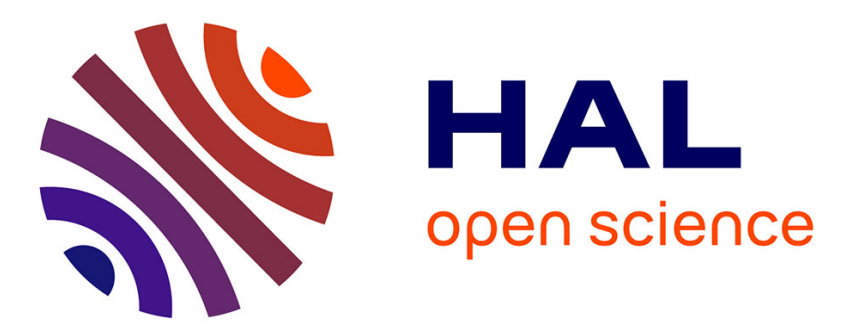

\title{
Neutronic and fuel cycle comparison of uranium and thorium as matrix for minor actinides bearing- blankets
}

\author{
T. Kooyman, L. Buiron
}

\section{To cite this version:}

T. Kooyman, L. Buiron. Neutronic and fuel cycle comparison of uranium and thorium as matrix for minor actinides bearing- blankets. Annals of Nuclear Energy, 2016, 92, pp.61-71. 10.1016/j.anucene.2016.01.020 . cea-02382796

\section{HAL Id: cea-02382796 https://hal-cea.archives-ouvertes.fr/cea-02382796}

Submitted on 27 Nov 2019

HAL is a multi-disciplinary open access archive for the deposit and dissemination of scientific research documents, whether they are published or not. The documents may come from teaching and research institutions in France or abroad, or from public or private research centers.
L'archive ouverte pluridisciplinaire HAL, est destinée au dépôt et à la diffusion de documents scientifiques de niveau recherche, publiés ou non, émanant des établissements d'enseignement et de recherche français ou étrangers, des laboratoires publics ou privés. 
Neutronic and fuel cycle comparison of uranium and thorium as matrix for minor actinides bearingblankets

Abstract:

Minor actinides transmutation is one of the three main axes defined by the 2006 French law for nuclear waste management, along with long-term storage and use of a deep geological repository. In the heterogeneous approach, minor actinides are loaded in specially designed targets assemblies which are located in the periphery of the core, in order to limit the impacts on core operations. In this paper, we compare the use of uranium and thorium dioxide as support matrix in which minor actinides are diluted in the target assemblies. Both $\mathrm{UO}_{2}$ and $\mathrm{ThO}_{2}$ exhibit sufficiently good irradiation behavior to withstand the long residence time associated with heterogeneous transmutation. Five different reprocessing strategies are compared in which some or all the elements in the blankets are reused after reprocessing. The impacts on core safety parameters and fuel cycle parameters are also evaluated for each case and it is found that using thorium as support matrix with reuse of uranium 233 leads to transmutation performances similar to the one obtained with the reuse of plutonium from uranium blankets with slightly lower global impacts on reactor operation and fuel cycle.

Introduction:

Minor actinides are a set of three main elements (neptunium, americium and curium) which are byproducts of uranium irradiation in nuclear reactors. These elements are produced in relatively limited quantities [1] but they exhibit long-term radiotoxicity and decay heat levels which complicate the handling of associated nuclear waste.

In the case of a closed nuclear fuel cycle strategies where spent fuel is reprocessed and plutonium reused in fast spectrum reactors, minor actinides are the main contributors to long term radiotoxicity of the spent fuel and to decay heat of the ultimate waste package. Minor actinides transmutation has thus been proposed as a potential solution to decrease the burden of nuclear waste and to reduce the constraint on the final repository. [2]

Transmutation in critical reactors can be done in two different ways:

- Homogeneous transmutation, in which minor actinides are directly mixed with the reactor fuel. This solution exhibits the best performances as the minor actinides are exposed to a high flux level. However, it exhibits the drawback of contaminating the entire fuel cycle with minor actinides and it decreases the "safety" performances of the reactor. Minor actinides content of up to $5 \% \mathrm{vol}$ can be loaded depending on the considered core design. Additionally, the residence time of the minor actinides bearing fuels can not exceed the one of standard MOX fuel.

- Heterogeneous transmutation in which minor actinides can be loaded in specifically designed assemblies, usually in the periphery of the core, which are called "Minor Actinides Bearing Blankets" or MABB. The use of such subassemblies helps decoupling minor actinides management from the fuel and thus gives a larger flexibility compared to the homogeneous mode. As these blankets benefit from the neutron leakage from the active zone they have almost no impact on the core neutronic parameters such as delayed neutron fractions or sodium void worth. This allows to load a large minor actinide mass and to reduce the 
number of MABB to be manufactured. On the other hand, the obtained performances are lower than the previous one as the flux level seen by the assemblies is quite low. Minor actinides content between $10 \%$ and $40 \%$ are expected to be loaded in such cores. As fuel and MABB cycles are decoupled, higher transmutation rates can be expected at the cost of longer irradiation time.

The present paper focuses on heterogeneous transmutation strategies. A thorough analysis of this transmutation approach has been carried out by a NEA task force in 2009 and summarized in [3]. The main points are described below:

- The high content of minor actinides in the fuel requires important fuel design effort, notably in terms of mechanical design. Previous experiments, especially the SUPERFACT experiment in which pins with up to $45 \%$ of americium and neptunium were irradiated in the Phenix reactor core [4] showed that MABB irradiation was accompanied by an important production of Helium due to alpha decay of minor actinides nuclei which has an impact on the mechanical behavior of the pin and on the size of the gas plenum.

- Power production in the MABB assemblies is also very low at the beginning of irradiation which puts tighter constraints on the mechanical design as fuel restructuration does not happen at low temperatures. The important power variation during irradiation also increases the strain on the fuel pins, possibly leading to thermal cracking. [5]

- Decay heat, gamma and neutron emission of irradiated and refabricated MABB assemblies is significantly higher than for a standard MOX fuel, which leads to additional issues in terms of fuel handling, reprocessing and manufacturing.

When considering minor actinides transmutation, several objectives are usually pursued. Firstly, the transmutation performances, e.g. the amount of minor actinides which are effectively turned into fission products during irradiation is considered, as it is a direct estimator of the performances of the process. The support ratio, which is the number of reactors which production can be absorbed in one minor actinide burner, is also of interest from an economic point of view. The support ratio can be reduced either by decreasing the production of minor actinides in the reactor or by increasing transmutation performances, as discussed here.

It has been proposed to add moderating material in the MABB in order to increase the transmutation performances of the design [6]. Slowing down the neutrons in the blankets has the interest of increasing the absorption cross sections and thus the number of captures or fissions. However, it also increases the amount of curium produced, which is more troublesome than americium on fuel back-end due to a higher neutron source and specific decay heat. This addition is especially interesting in case of once-through transmutation, in which the blankets are irradiated only once and then discarded as waste. We considered here a heterogeneous transmutation scheme in which irradiated blankets are reprocessed to maximize amount of transmuted material.

Similarly to plutonium, minor actinides cannot be loaded per se as oxide fuel in a reactor but must be blended with a matrix to produce usable reactor fuel. Several materials have been proposed as potential matrices for MABB fuels. The first one is evidently uranium dioxide $\left(\mathrm{UO}_{2}\right)$, which has been tested in the SUPERFACT experiments for instance. $\mathrm{UO}_{2}$ is a well-known material with a low swelling rate and which can withstand the long residence time associated with heterogeneous transmutation. However, the use of uranium oxide as support matrix comes with a production of 
plutonium which may cause an issue in terms of proliferation. It also implies a modification of the core to keep a total breeding gain close to unity. An analysis of the impact (or lack thereof) of the use of minor actinides blankets has been done in [7]. Additionally, the irradiation behavior of mixed uranium-minor actinides oxide fuel has yet to be fully characterized [8].

Inert Fuel Matrix, or IMF, has also been discussed for transmutation in heterogeneous mode. A review can be found in [9]. In this concept, the minor actinides are embedded as oxide in either a ceramic material (Cercer concept) or a metallic material (Cermet). This removes the production of plutonium due to capture by uranium 238 in the target but the selection of the matrix is complicated as it should exhibit a good thermal conductivity, acceptable swelling under irradiation and good irradiation resistance behavior to neutrons, alpha and fission products. No matrix has been found featuring all these parameters. However, a possible hybrid matrix of $\mathrm{AmZrO}_{2}$ dispersed in an $\mathrm{MgAl}_{2} \mathrm{O}_{4}$ matrix, which limits damage to $\mathrm{MgAl}_{2} \mathrm{O}_{4}$ by fission products irradiation while making good use of its otherwise good stability has been proposed in [10] . Issues regarding dissolution of the inert matrix must also be addressed (see for instance [11]).

Thorium has been proposed as a potential nuclear fuel in the Th232/U233 fuel cycle, in which fissile uranium 233 is bred from thorium 232. This cycle can be closed in fast or thermal reactors, although it requires an initial stock of fissile material (U235 or Pu239) to start the breeding process. The potential benefits coming from the use of this cycle are listed in [12]. To name but a few, this option virtually removes minor actinides production and increases the reserve in fertile material by a factor three to four as thorium is more abundant than uranium while being intrinsically proliferation resistant due to high gamma production of daughter isotopes of U232. India is currently the leading country for thorium fuel cycle industrialization. Thorium dioxide $\left(\mathrm{ThO}_{2}\right)$ or thoria is also a relatively well-known material which performances under irradiation are better than those of $\mathrm{UO}_{2}$. A detailed study of thorium properties as a nuclear fuel can be found in [13]

Thorium dioxide use has been already discussed as support matrix for heterogeneous transmutation in once-through scheme, for instance in [14]. In this case, advantage is taken of the low solubility of thoria in groundwater for long-term storage. Additionally, this option limits the production of plutonium in the blankets, thus decreasing the total radiotoxicity at disposal. Advantage has also been taken of the lack of plutonium to transmute plutonium and minor actinides without separation during reprocessing, in the case of it being not acceptable. The use of thorium axial blankets in such a case and the related neutronic impacts are discussed in [15].

We elaborate in this paper on the possibility of using thorium dioxide $\left(\mathrm{ThO}_{2}\right)$ as a support matrix for minor actinides bearing blankets in the case of a multi-reprocessing scheme in plutonium-fueled fast reactors. We compare the relative performances of uranium and thorium for this application in terms of reactor and fuel cycle impacts. The methodology and tools used are detailed in the first part and the effects of thorium and uranium matrixes on reactors parameters, fuel cycle and transmutation performances are then analyzed in the following sections.

Several cases can be envisioned for transmutation with a thorium support. We considered that thorium was used in combination with a conventional U/Pu fuel cycle. The following possibilities for thorium use which were investigated here are : 
- Thorium could be used only as support matrix and the bred uranium 233 can be recovered after reprocessing and used for starting an independent thorium/uranium cycle. As this cycle requires an initial supply of uranium 233 for starting, this solution would allow a reduction of the total inventory of minor actinides during the switch to thorium while producing the necessary uranium 233. Similarly, the uranium production could be incorporated in the reactor core as fuel, thus replacing part of the plutonium and decreasing the minor actinides production. This option was not pursued here.

- Uranium 233 produced during irradiation could be reused as a neutron supplier directly in the blankets, in order not to mix plutonium and uranium 233 in the standard fuel cycle. In this approach, plutonium from the blankets is recovered to be used in the reactor core while uranium, thorium and minor actinides are left in the blankets. The transmutation performances would then benefit from the presence of fissile material in the blanket without requiring plutonium for this purpose, thus limiting the increase in the plutonium inventory.

- Finally, thorium could be used in conjunction with a reprocessing scheme which prevent recovery of potential proliferating materials [16] [17], in which case all the elements produced during irradiation would be recovered together and incorporated again into MABB. This case totally separates the management of the fuel cycle and of the blankets.

We compared those strategies with two similar ones using uranium dioxide as support matrix:

- The direct one in which $\mathrm{UO}_{2}$ is used as matrix and plutonium is recovered during reprocessing for use in the reactor core. Minor actinides are then reincorporated in fresh blankets. This strategy is currently envisioned in France as discussed in [18].

- The TRU approach in which there is a complete separation of the driver fuel cycle from the blankets fuel cycle. This approach is promoted by the USA in which plutonium and minor actinides are not separated in order to remove any proliferation issues. Plutonium is considered as a minor actinide in this case and treated as such. An example of implementation of this strategy is discussed in [19].

\section{Methodology}

Neutronic calculations were performed using the ERANOS code package [20]. The starting point of the calculations was a critical homogeneous SFR core developed jointly by CEA, EDF and Areva and detailed below in Table 1. The core was described using 2D-RZ geometry with a homogeneous description of the various core mediums. Calculations were based on the nuclear data library JEFF 3.1 [21]. A layout of the core is given in Figure 1. The plutonium content was tuned to fulfill a reactivity criteria at the end of cycle $\left(\rho_{\mathrm{FC}}=750 \mathrm{pcm}\right)$. Calculations were done using with the transport equation with a 33-group energy mesh. The design of the target assembly and fuel pin is still underway so the analysis was done with $38 \%$ in volume of heavy metals in the target assemblies, which is deemed representative of the expected result. 
Table 1: Characteristics of the SFR V2b core used for the calculations [22]

\begin{tabular}{|l|l|}
\hline Main characteristics of SFR V2b \\
\hline Power (MWTh/MWe) & $3600 / 1450$ \\
\hline Number of fissile assemblies (Internal core/External core) & $453(267 / 186$ ) \\
\hline Number of assemblies in the first outer ring (MABB) & 84 \\
\hline Residence time & $5 \times 410=2050 \mathrm{EPFD}$ \\
\hline Volume fractions & $\begin{array}{l}43.7 \% \mathrm{UPuO}_{2}, 27.5 \% \mathrm{Na}, 8.2 \% \\
\mathrm{Wrapper}_{1} 11.9 \% \text { cladding }\end{array}$ \\
\hline Fuel nature & $\mathrm{UPuO}_{2}$ \\
\hline Plutonium content(mean/IC/EC) \%vol & $15.80 \% / 14.65 \% / 17.44 \%$ \\
\hline Effective breeding ratio & 1 \\
\hline
\end{tabular}

Transmutation performances were evaluated using the two following estimators:

- Transmutation rate calculated between the beginning of irradiation and after 5 years of cooling and 2 years of manufacturing : $\frac{\text { initial mass of MA-final mass of MA }}{\text { initial mass of MA }} * 100$

- Support ratio, which is defined as the ratio of the minor actinides consumption in the blankets with $20 \%$ MA loaded, divided by the production in the reactor core alone. This indicates the number of reactors which minor actinides production can be transmuted using one reactor equipped with radial blankets.

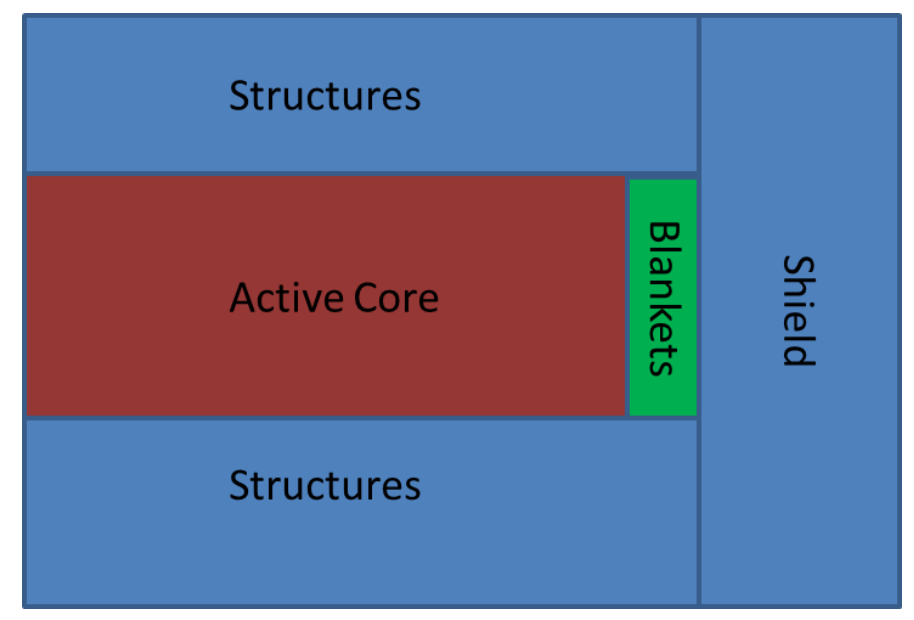

Figure 1 : 2D-RZ representation of the SFR-V2B core with minor actinides bearing blankets

Minor actinides loading was done with a minor actinides vector hereafter labelled "MA2035" and given in Table 2. This isotopic vector is deemed representative of the minor actinides feed available by 2035 in France considering the foreseen evolution of the French PWR fleet. The plutonium vector used for the calculations, given in Table 3 was also considered representative at the same time scale. 


\begin{tabular}{|l|l|l|l|l|l|l|l|l|l|}
\hline Element & Np237 & Am241 & Am242m & Am243 & Cm242 & Cm243 & Cm244 & Cm245 & Cm246 \\
\hline $\begin{array}{l}\text { Fraction } \\
\text { (\%mass) }\end{array}$ & 16.87 & 60.62 & 0.24 & 15.7 & 0.02 & 0.07 & 5.14 & 1.26 & 0.08 \\
\hline
\end{tabular}

Table 2 : Isotopic vector used for minor actinides

\begin{tabular}{|c|c|c|c|c|c|c|}
\hline Isotope & Pu238 & Pu239 & Pu240 & Pu241 & Pu242 & Am241 \\
\hline $\begin{array}{l}\text { Fraction } \\
\text { (\%mass) }\end{array}$ & 3.57 & 47.39 & 29.66 & 8.23 & 10.37 & 0.78 \\
\hline
\end{tabular}

Table 3 : Isotopic vector used for plutonium

Minor actinides bearing assemblies were loaded in the first outer ring of the core in substitution of the first reflector ring. Their residence time was twice the one of standard fuel assemblies in order to compensate for the associated low flux level. This amounted to 4100 EPFD, i.e. 10 reactor cycles. In the uranium matrix case, at the end of the irradiation, blankets were reprocessed with 5 years cooling time and 2 years manufacturing time. The plutonium was removed from the blankets and mixed with the core production. Uranium is reused as matrix for the blankets. The minor actinides content in the blankets was recompleted using the minor actinides vector coming from the core production in order to keep the loaded mass constant over two cycles. The external feed of minor actinides is assumed to come from similar reactors without radial blankets. Mass balance is then achieved using uranium. This strategy will be called as U/Pu/MA in the following. It is shown in Figure 2 . In the thorium case, blankets were reprocessed on the same time scale with the plutonium being recovered and added to the plutonium of the core. The uranium produced during irradiation, mainly uranium 233, is taken out of the blankets while minor actinides are recompleted using the minor actinides vector from the core. This strategy will be called Th/U-Pu/MA in the following. The uranium here produced could be mixed with plutonium and used as fuel but this option was not investigated here. It is also shown in Figure 2.

A third strategy was investigated in which thorium is used as support matrix and uranium is left in the blankets along with minor actinides and plutonium is removed for use in the reactor core. This strategy is denominated Th(U)/Pu/MA. The feasibility of thorium/U/Pu separation still yet has to be demonstrated, as discussed in [12], so it is possible that this strategy may incur penalties in terms of reprocessing losses.

A final situation in which the blankets are reprocessed on a Th(U)/TRU basis was also studied. In this case, uranium, plutonium and minor actinides from the blankets are kept in the blankets. Minor actinides with the core isotopic composition are then added to the blankets up to $20 \%$ of minor actinides and mass balance is achieved with thorium. A similar strategy named U/TRU was also studied, which is similar to the Th(U)/TRU one, with all the transuranics being kept in the blanket. As said before, this strategy completely separates the driver and the blankets fuel cycles and reduces the proliferation risks. All these strategies are shown in Figure 3. 


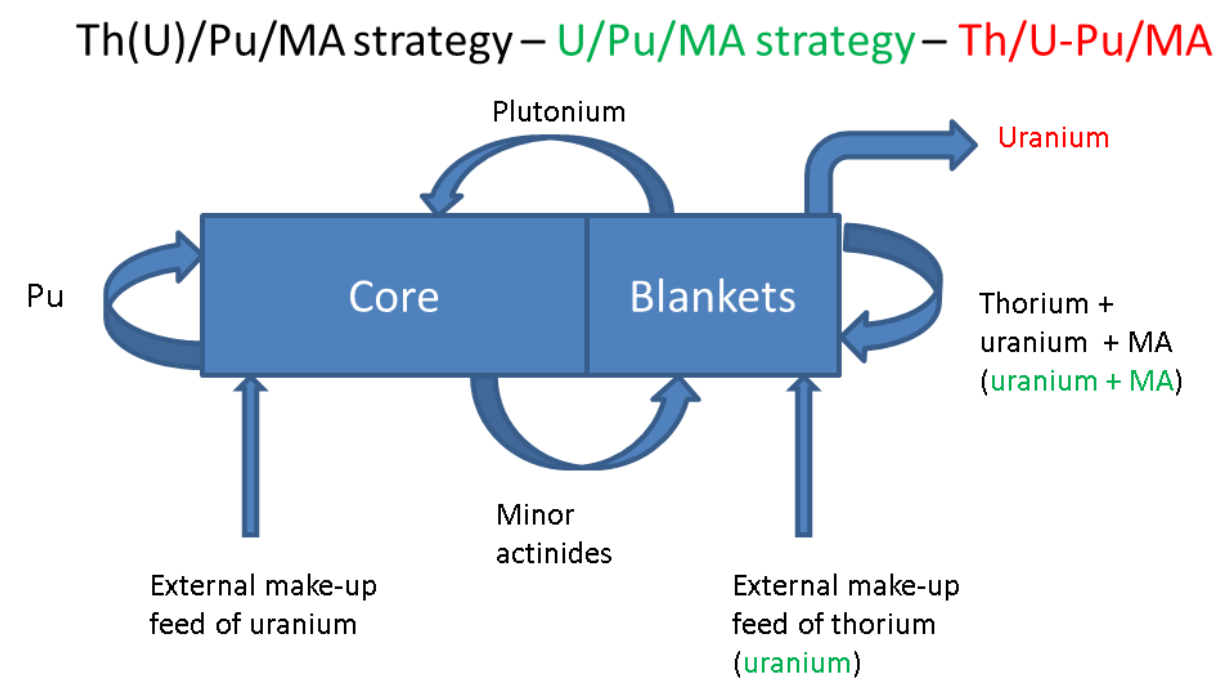

Figure 2 : Outline of the Th(U)/Pu/MA, U/Pu/MA and Th/U-Pu/MA strategies

\section{Th(U)/TRU strategy - U/TRU strategy}

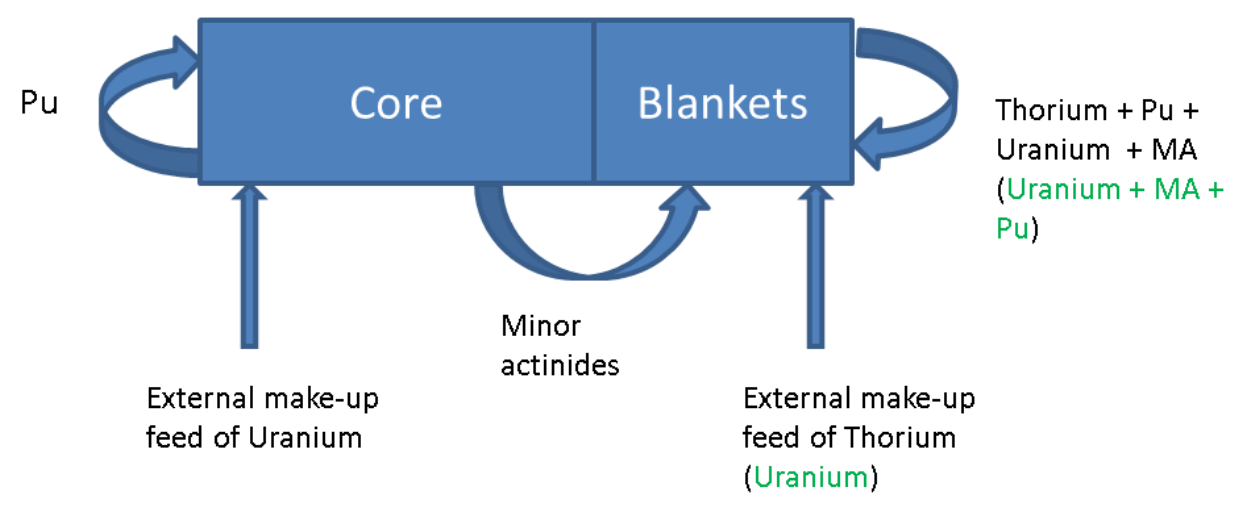

Figure 3 : Outline of the Th(U)/TRU and U/TRU strategies

The whole system was taken to equilibrium and characterized both at the end of the first 10 irradiation cycles and at equilibrium. The equilibrium is reached when the transmutation performances over two consecutive cycles are identical. We denominated as EOEC the end of a MABB equilibrium cycle.

The minor actinides content is stalled to $20 \%$ which corresponds to $2375 \mathrm{~kg}$ of minor actinides (heavy nuclides mass) in both cases. For perspective, the current minor actinides production of the French nuclear fleet amounts to 1.2 tons a year. The minor actinides isotopic vector of the core production is used as make-up feed to reach the $20 \%$ limit which is currently considered by CEA [7]. 
The use of thorium as matrix material was analyzed through its impacts on the core parameters such as breeding gain, transmutation performances, sodium void worth and Doppler Effect and on the fuel cycle with neutron and gamma source, decay heat, radiotoxicity estimated.

2. Comparison of uranium and thorium as support matrix for MABB : transmutation performances

a. Transmutation rate

The first parameter of interest with regards to transmutation performances is the transmutation rate, which can be related to the efficiency of the transmutation process. Several comments can be made on Figure 4. The options $\mathrm{U} / \mathrm{Pu} / \mathrm{Ma}$ and $\mathrm{Th} / \mathrm{U}-\mathrm{Pu} / \mathrm{MA}$, which correspond to the case where only the minor actinides are left in the blankets, yield the lowest transmutation rate. Indeed, for these two strategies, no fissile material is initially present in the blankets. Consequently, the neutron production in situ is limited compared to the other cases, which in turn limits the transmutation performances. The thorium case is slightly lower than the uranium one as the thorium mass in the blankets is inferior to the uranium mass due to the thoria density being only $10 \mathrm{~g} . \mathrm{cm}^{-3} \mathrm{compared}$ to $10.95 \mathrm{~g} . \mathrm{cm}^{-3}$ for uranium dioxide. This leads to a lower production of fissile material during irradiation and thus a slightly lower transmutation rate.

In all the three other cases, fissile materials are left in the blanket during reprocessing. The transmutation rate is then directly proportional to the amount of fissile material in the blanket. For the Th(U)/Pu/MA strategy, the fraction of U233 in the blanket is $7 \%$ and for the two TRU cases, volume fractions of "fissile" material (U233, U235, Pu239 and Pu241) at the beginning of irradiation at equilibrium are respectively $7.8 \%$ and $8.0 \%$ for Th/U(TRU)) and Th(TRU).

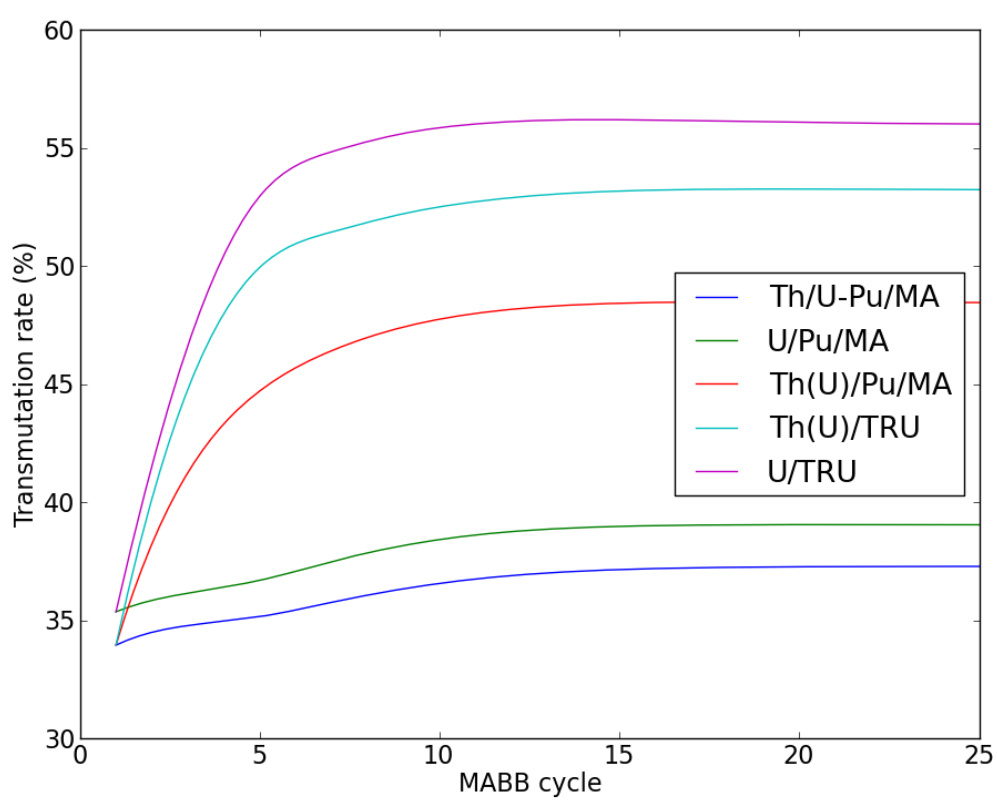

Figure 4 : Evolution of the transmutation rates in the MABB

The increase in the transmutation performances is directly linked to the increase in fissile material in the blanket assembly. The latter has two mutually opposing effects on the neutron spectrum in the blankets. On the one hand, the increase in the flux level leads to a direct increase in the reaction 
rate, while on the other hand, the spectrum hardening leads to a decrease in the absorption cross section, thus decreasing the transmutation rate.

To evaluate the magnitude of each effect, the same calculations were carried out over 410 EPFD using a simplified depletion equation while varying in turns the spectrum and the flux level. Two calculations were performed with the neutron spectrum from the U/Pu/MA case and two different flux levels and the same jobs were performed again with the Th(U)/Pu/MA spectrum.

Table 4 : Comparison of the one-group cross sections between the uranium and thorium case

\begin{tabular}{|c|c|c|}
\hline \multicolumn{3}{|c|}{ uranium } \\
\hline Isotope & Capture (b) & Fission (b) \\
\hline Th232 & $4.46 \mathrm{E}-01$ & $1.00 \mathrm{E}-02$ \\
\hline U233 & $2.69 \mathrm{E}-01$ & $2.81 \mathrm{E}+00$ \\
\hline U238 & $2.94 \mathrm{E}-01$ & $3.96 \mathrm{E}-02$ \\
\hline Pu239 & $5.77 \mathrm{E}-01$ & $1.86 \mathrm{E}+00$ \\
\hline Np237 & $1.72 \mathrm{E}+00$ & $3.07 \mathrm{E}-01$ \\
\hline Am241 & $1.96 \mathrm{E}+00$ & $2.51 \mathrm{E}-01$ \\
\hline Am243 & $1.76 \mathrm{E}+00$ & $1.83 \mathrm{E}-01$ \\
\hline Cm244 & $9.14 \mathrm{E}-01$ & $3.88 \mathrm{E}-01$ \\
\hline
\end{tabular}

\begin{tabular}{|c|c|c|}
\hline \multicolumn{3}{|c|}{ thorium } \\
\hline Isotope & Capture (b) & Fission (b) \\
\hline Th232 & $3.33 \mathrm{E}-01$ & $1.17 \mathrm{E}-02$ \\
\hline U233 & $2.51 \mathrm{E}-01$ & $2.69 \mathrm{E}+00$ \\
\hline U238 & $4.06 \mathrm{E}-01$ & $4.64 \mathrm{E}-02$ \\
\hline Pu239 & $5.32 \mathrm{E}-01$ & $1.86 \mathrm{E}+00$ \\
\hline Np237 & $1.55 \mathrm{E}+00$ & $3.50 \mathrm{E}-01$ \\
\hline Am241 & $1.81 \mathrm{E}+00$ & $2.89 \mathrm{E}-01$ \\
\hline Am243 & $1.60 \mathrm{E}+00$ & $2.12 \mathrm{E}-01$ \\
\hline Cm244 & $8.31 \mathrm{E}-01$ & $4.38 \mathrm{E}-01$ \\
\hline
\end{tabular}

Comparison of the spectra in the blankets for U/Pu/MA and Th(U)/Pu/MA

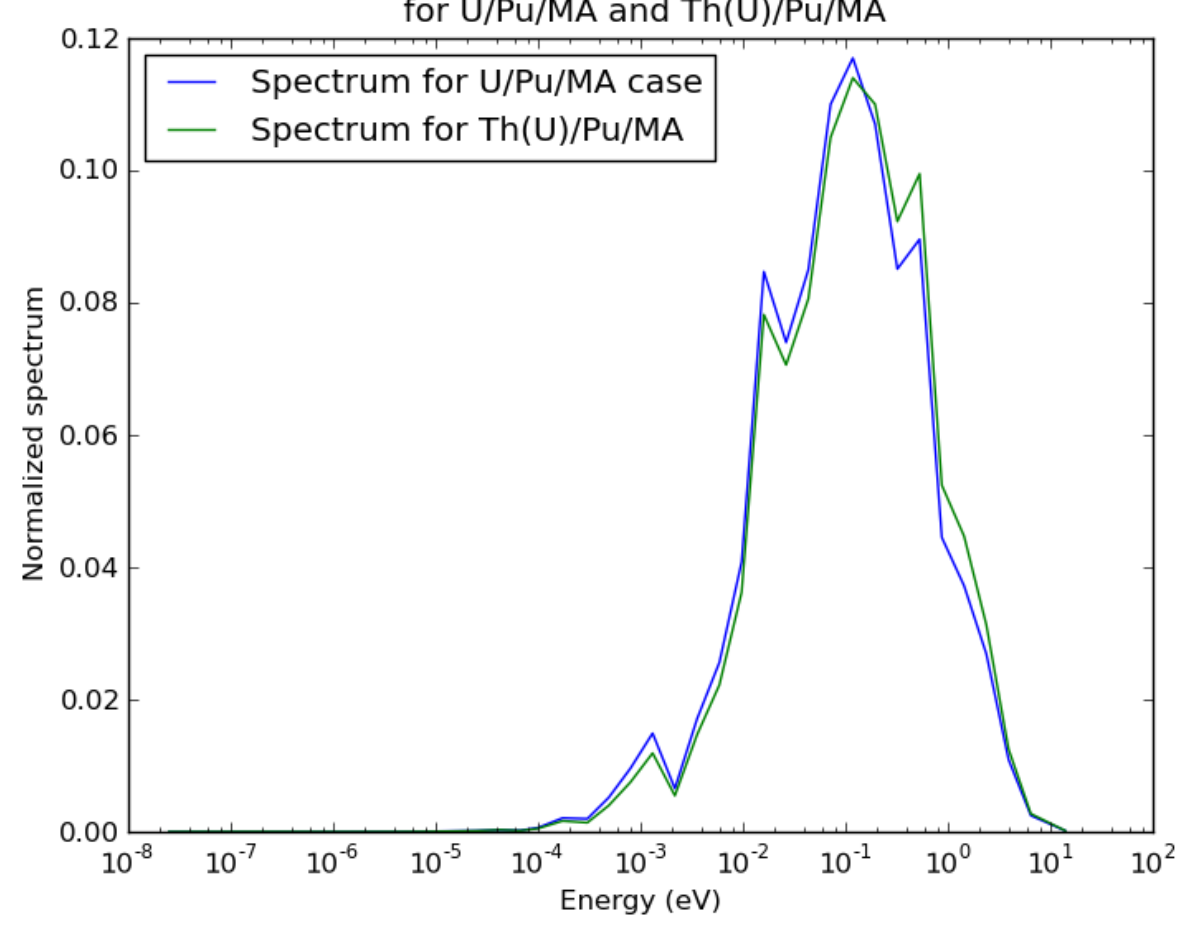

Figure 5 : Difference between the spectrum in the blankets in the thorium case and in the uranium case 
Table 5 : Comparison of the effect of cross sections variations and flux levels on transmutation rate over one cycle

\begin{tabular}{|c|c|c|c|c|}
\hline \multirow{2}{*}{$\begin{array}{c}\text { Transmutation rate } \\
(\%)\end{array}$} & \multicolumn{2}{|c|}{$\begin{array}{c}\text { Flux level of Uranium case : 9e14 } \\
\mathrm{n} / \mathrm{cm}^{2} / \mathrm{s}\end{array}$} & \multicolumn{2}{c|}{$\begin{array}{c}\text { Flux level of Thorium case : } 1,2 \mathrm{e} 15 \\
\mathrm{n} / \mathrm{cm}^{2} / \mathrm{s}\end{array}$} \\
\cline { 2 - 5 } & $\begin{array}{c}\text { Uranium } \\
\text { Spectrum }\end{array}$ & $\begin{array}{c}\text { Thorium } \\
\text { Spectrum }\end{array}$ & $\begin{array}{c}\text { Uranium } \\
\text { Spectrum }\end{array}$ & $\begin{array}{c}\text { Thorium } \\
\text { Spectrum }\end{array}$ \\
\hline Support U & $-5,2$ & $-5,12$ & $-6,39$ & $-6,28$ \\
\hline Support Th & $-5,27$ & $-5,19$ & $-6,43$ & $-6,33$ \\
\hline
\end{tabular}

Looking at Table 5, we can see that the impact of the spectrum hardening is limited to around $-0.1 \%$ point in the transmutation rate. Looking at the impact of the flux level, we can see it is dominant compared to the spectrum effect, and that is this effect which explains the increase in transmutation performances.

\section{b. Support ratio}

The results for support ratio evaluation are given in Table 6 . Similarly to what can be seen on Figure 4, obviously the strategies where fissile materials are left in the blankets are more effective than the two strategies without fissile material. We can also see that the U/TRU approach yields the best support ratio. As the core production of minor actinides is nearly not impacted by the presence of minor actinides bearing blankets, the support ratio is proportional to the transmutation rate.

Table 6 : Support ratio for each strategy at equilibrium

\begin{tabular}{|l|l|l|l|l|l|}
\hline Strategy & Th/U-Pu/MA & U/Pu/MA & Th(U)/Pu/MA & Th(U)/TRU & U/TRU \\
\hline Support ratio & 1.61 & 1.77 & 2.2 & 2.55 & 2.68 \\
\hline
\end{tabular}

3. Comparison of uranium and thorium as support matrix for MABB : impact on core parameters

a. Core operation parameters

The impacts of each strategy on core operation parameters are given in Table 7. The reactivity swing in the thorium case is higher at the beginning of irradiation than for uranium as thorium is more capturing than uranium and the build-up of plutonium 239 and uranium 233 occurs in the first cycles. At equilibrium, the reactivity swing is higher for the case with fissile material in the blankets as these blankets act like fuel assemblies. Conversely, the average burn-up is lower as power production is spread over one more ring of assemblies.

The cases where thorium and uranium 233 are kept in the blankets have a lower impact on the core sodium void worth as the $v$-factor (neutron production per fission vs energy) of U233 dependency on the neutron energy is flatter than to the one of plutonium at high energy. Consequently, in case of coolant voiding, the contribution of the blankets to the total sodium void worth is lower. The case with uranium leads to a higher power production in the blankets by $8 \%$ at equilibrium which is due to the higher content in fissile material in this case. During the first cycles, both cases are equivalent. In both fissile-free cases (U/Pu/MA and Th/UPu/MA), the breeding gain is increased by 0.1 due to the presence of fertile blankets. In the other case, the breeding gain only increase by a factor six to 
eight as fissile material is already present in the blankets. This residual increase is mainly explained by production of more fissile isotope such as plutonium 238 during the transmutation process.

Table 7 : Impact of the support on core parameters (MA 2035 vector, no moderating material, FC $=$ fifth cycle, EQ = equilibrium cycle)

\begin{tabular}{|c|c|c|c|c|c|c|}
\hline Parameters & $\begin{array}{l}\text { SFR } \\
\text { V2B } \\
\text { Core } \\
\text { (453 } \\
\text { S/A) } \\
\end{array}$ & $\begin{array}{l}\text { Th/U- } \\
\text { PU/MA }\end{array}$ & $\mathrm{U} / \mathrm{Pu} / \mathrm{MA}$ & $\mathrm{Th}(\mathrm{U}) / \mathrm{Pu} / \mathrm{MA}$ & $\operatorname{Th}(U) / T R U$ & U/TRU \\
\hline $\begin{array}{l}\text { Reactivity swing } \\
\quad(\mathrm{FC})(\mathrm{pcm})\end{array}$ & \multirow{2}{*}{-450} & -518 & -419 & -518 & -518 & -419 \\
\hline $\begin{array}{l}\text { Reactivity swing } \\
\text { (EQ) (pcm) }\end{array}$ & & -153 & -108 & -151 & -240 & -241 \\
\hline $\begin{array}{c}\text { Mean Burn-up, FC } \\
(\mathrm{GWd} \backslash \mathrm{tHM})\end{array}$ & \multirow{2}{*}{99} & 97 & 97 & 97 & 97 & 97 \\
\hline $\begin{array}{c}\text { Mean Burn-up, EQ } \\
(\mathrm{GWd} \backslash \mathrm{tHM})\end{array}$ & & 93 & 93 & 87 & 83 & 82 \\
\hline Max DPA (FC) & \multirow{2}{*}{149} & 156 & 156 & 157 & 157 & 156 \\
\hline Max DPA (EQ) & & 150 & 149 & 149 & 152 & 155 \\
\hline $\begin{array}{l}\text { Sodium void worth } \\
(\mathrm{pcm})(\mathrm{FC})\end{array}$ & \multirow{2}{*}{1790} & 1808 & 1818 & 1808 & 1808 & 1820 \\
\hline $\begin{array}{l}\text { Sodium void worth } \\
\text { (pcm) (EQ) }\end{array}$ & & 1814 & 1821 & 1791 & 1783 & 1837 \\
\hline $\begin{array}{l}\text { Doppler Effect } \\
\text { Magnitude (pcm) } \\
\text { (FC) }\end{array}$ & \multirow[t]{2}{*}{-441} & -430 & -440 & -430 & -430 & -434 \\
\hline $\begin{array}{l}\text { Doppler effect } \\
\text { (pcm) (EQ) }\end{array}$ & & -444 & -448 & -443 & -428 & -424 \\
\hline $\begin{array}{l}\text { Breeding gain } \\
\text { (total/blankets) } \\
\text { (FC) }\end{array}$ & \multirow[t]{2}{*}{0.009} & $0.088 / 0.093$ & $0.086 / 0.082$ & $0.088 / 0.093$ & $0.088 / 0.093$ & $0.086 / 0.082$ \\
\hline $\begin{array}{c}\text { Breeding gain } \\
\text { (total/blankets)(EQ) }\end{array}$ & & $0.106 / 0.039$ & $0.103 / 0.058$ & $0.078 / 0.029$ & $0.063 / 0.008$ & $\begin{array}{c}0.062 /- \\
0.001\end{array}$ \\
\hline $\begin{array}{c}\text { Fraction of power } \\
\text { in blankets at EOC } \\
(\%)(\mathrm{FC})\end{array}$ & 0 & 2.1 & 2.4 & 2.1 & 2.1 & 2.4 \\
\hline $\begin{array}{c}\text { Fraction of power } \\
\text { in blankets at EOC } \\
(\%)(E Q)\end{array}$ & 0 & 5.4 & 5.64 & 10.5 & 13.5 & 14.7 \\
\hline
\end{tabular}

b. Inventory in the blankets

The evolution of the heavy nuclides content in the blankets is given in Figure 6 . The behavior of each element can be divided into two consecutive patterns constituted of a first irradiation phase of 4100 EPFD followed by a second one of similar-length. Then, the blankets composition is evolved for 2555 days to simulate reprocessing and the blankets are recompleted using the minor actinides vector from the core production (also after 2555 days of decay) to achieve $2375 \mathrm{~kg}$ of MA in the blankets. 
Mass balance is achieved using the support element. Cooling time was omitted on Figure 6 for clarity.

Thorium and uranium in the cases where they are used as support matrix behave similarly. Their mass decreases during irradiation and are stable during decay phase. Both the time necessary to reach an equilibrium situation and the amount of thorium/uranium in the blankets depends on the amount of fissile elements in the blankets. Both Th/U-Pu/MA and U/Pu/MA reaches equilibrium after on complete MABB cycle (10 reactor cycles). Cases where fissile material is present in the blankets require a longer time to achieve equilibrium.
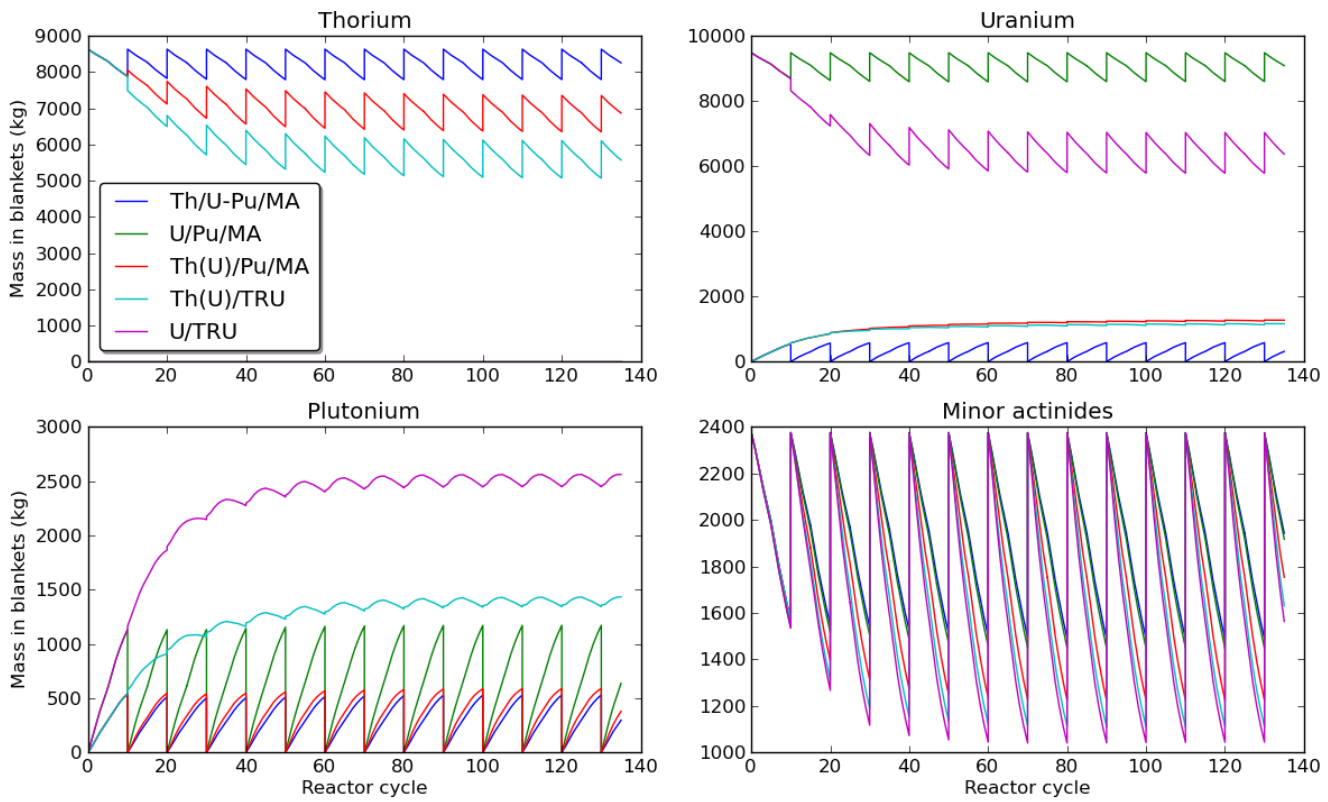

Figure 6 : Evolution of the Th, U, Pu and MA content in the blankets vs reactor cycle. Cooling and manufacturing were not plotted.

Regarding uranium evolution, it should be noted that the uranium mass in the Th(U)/TRU or $\mathrm{Th}(\mathrm{U}) / \mathrm{Pu} / \mathrm{MA}$ is remarkably stable during irradiation, which will have a positive effect on power variation in the blankets during irradiation. Considering plutonium production, it is interesting to observe that half of the plutonium production in the $\mathrm{U} / \mathrm{Pu} / \mathrm{MA}$ case is coming from minor actinides transmutation, especially from the reaction ${ }_{95}^{241} \mathrm{Am}+n \rightarrow{ }_{96}^{242} \mathrm{Cm} \stackrel{\alpha}{\rightarrow}{ }_{94}^{238} \mathrm{Pu}$. Using thorium as support matrix consequently halves the production of plutonium in the blankets and the related inventory. Regarding the evolution of minor actinides mass in the blankets, the behavior of each curve on Figure 6 is directly related to the transmutation rate plotted on Figure 4.

The uranium 233 vector is slightly different between the Th(U)/Pu/MA and Th(U)/TRU cases with respectively 63 and $53 \%$ of uranium 233. The exact composition is given in Figure 7 at EOEC. It can be seen that the fraction of U232, which has a strong gamma emitter in its decay chain is the same in both cases. 

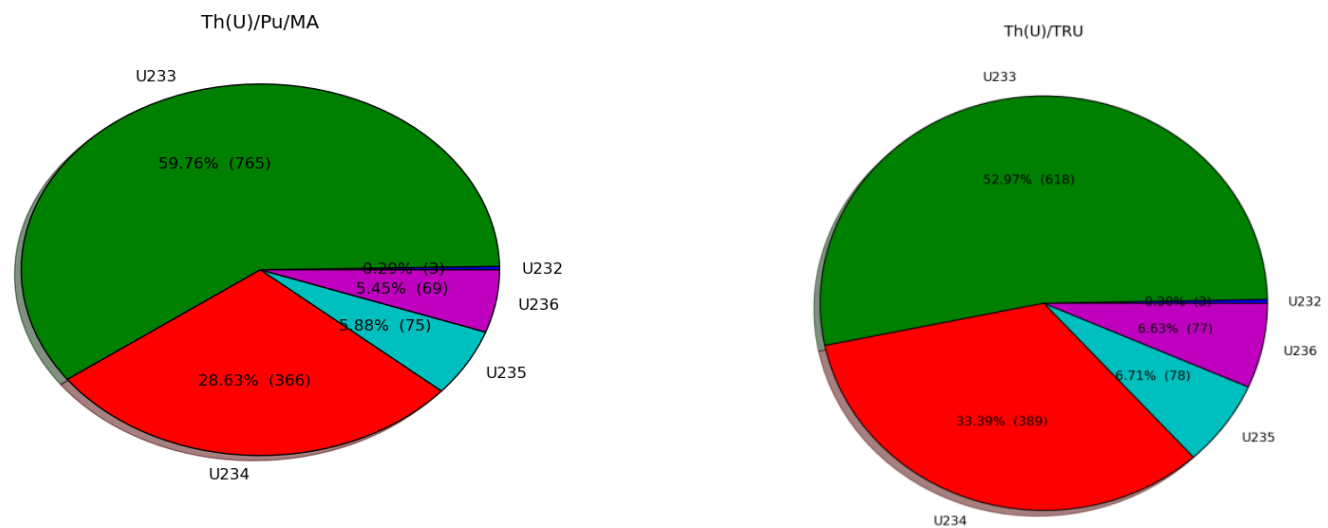

The plutonium isotopic vector is however widely varying between the various cases. As it can be seen in Figure 8, the Pu239 content in the thorium cases is very limited, making the plutonium useless for reactor use without dilution with higher-grade plutonium. This plutonium could for instance be used as denaturing material for military grade plutonium [23] or mixed with high-grade plutonium depending on the considered limits for proliferation resistance. It should be noted that the total mass of plutonium 238, which is the main responsible for decay heat at the reprocessing time-scale is similar between the two cases, as this production is related to the transmutation process and not to the breeding on the support.
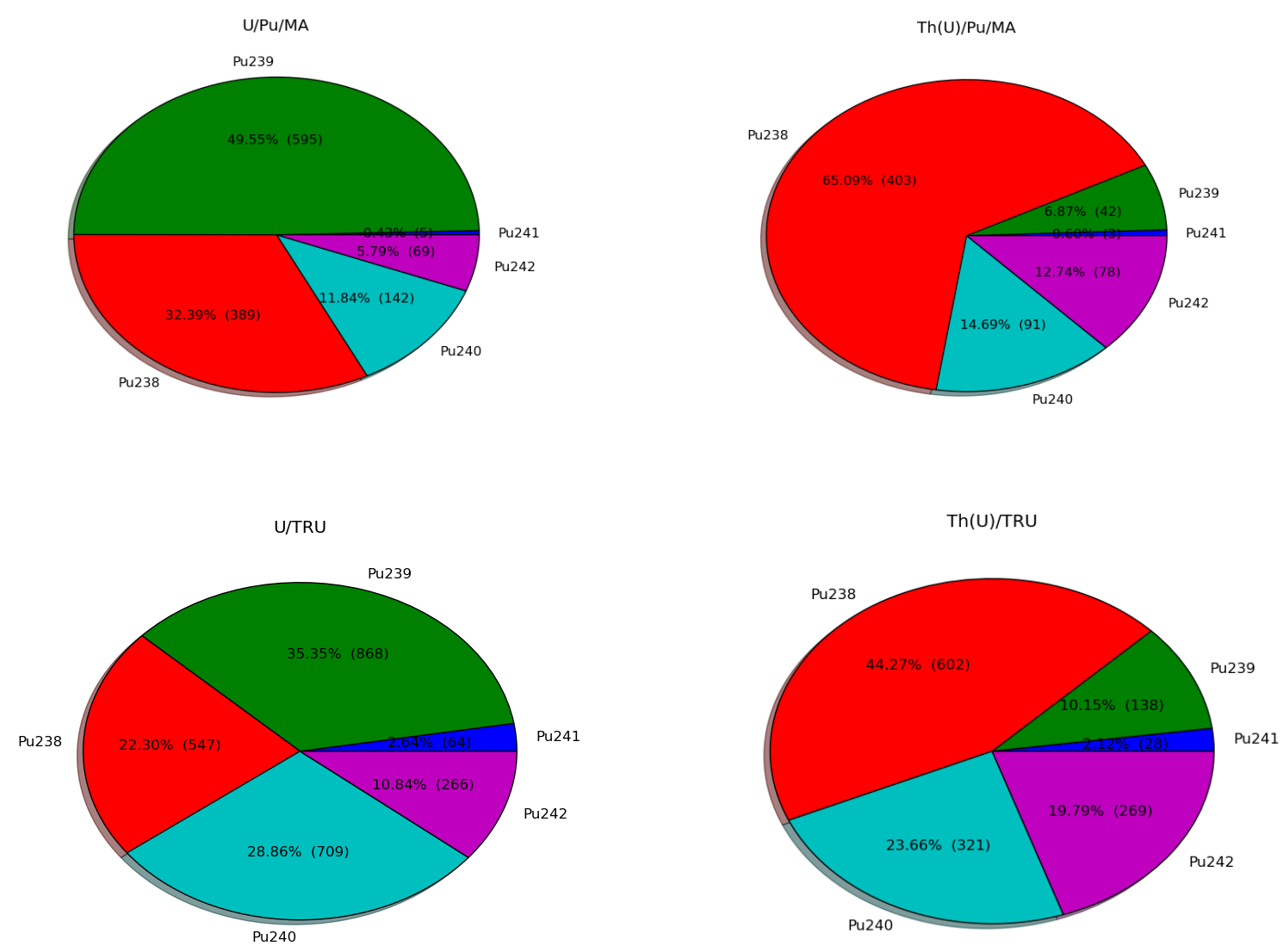
Figure 8 : Plutonium isotopic vector at equilibrium for U/Pu/MA, Th(U)/PuMA, U/TRU and Th(U)/TRU. The case $\mathrm{Th} / \mathrm{UPu} / \mathrm{MA}$ is similar to the Th(U)/Pu/MA in terms of isotopic vector.

\begin{tabular}{|c|c|c|c|c|c|}
\hline mass in $\mathrm{kg}$ & $\begin{array}{c}\text { Th/U- } \\
\mathrm{Pu} / \mathrm{MA}\end{array}$ & $\mathrm{U} / \mathrm{Pu} / \mathrm{MA}$ & $\mathrm{Th}(\mathrm{U}) / \mathrm{Pu} / \mathrm{MA}$ & $\mathrm{Th}(\mathrm{U}) / \mathrm{TRU}$ & $\mathrm{U} / \mathrm{TRU}$ \\
\hline $\mathrm{Np237}$ & 211.2 & 225.8 & 175.2 & 137.8 & 124.4 \\
\hline Am241 & 694.9 & 667.0 & 543.4 & 458.1 & 401.1 \\
\hline $\mathrm{Am} 242 \mathrm{~m}$ & 69.5 & 70.1 & 57.4 & 49.6 & 43.8 \\
\hline Am243 & 225.3 & 203.8 & 176.1 & 187.6 & 183.7 \\
\hline $\mathrm{Cm} 242$ & 0.2 & 0.2 & 0.2 & 0.1 & 0.1 \\
\hline $\mathrm{Cm} 243$ & 2.5 & 2.6 & 2.8 & 2.9 & 2.9 \\
\hline $\mathrm{Cm} 244$ & 140.2 & 134.8 & 135.4 & 145.7 & 157.6 \\
\hline $\mathrm{Cm} 245$ & 48.2 & 47.0 & 45.3 & 47.3 & 52.5 \\
\hline $\mathrm{Cm} 246$ & 36.6 & 35.9 & 31.7 & 31.1 & 34.5 \\
\hline $\mathrm{Cm} 247$ & 7.5 & 7.4 & 6.0 & 5.7 & 6.3 \\
\hline $\mathrm{Cm} 248$ & 5.4 & 5.7 & 4.8 & 4.5 & 4.9 \\
\hline Total & 1441.5 & 1400.3 & 1178.2 & 1070.4 & 1011.7 \\
\hline
\end{tabular}

\begin{tabular}{|c|c|c|c|c|c|}
\hline frac in \% & Th/U-Pu/MA & $\mathrm{U} / \mathrm{Pu} / \mathrm{MA}$ & $\mathrm{Th}(\mathrm{U}) / \mathrm{Pu} / \mathrm{MA}$ & $\mathrm{Th}(\mathrm{U}) / \mathrm{TRU}$ & $\mathrm{U} / \mathrm{TRU}$ \\
\hline $\mathrm{Np237}$ & 14.65 & 16.12 & 14.87 & 12.87 & 12.29 \\
\hline $\mathrm{Am} 241$ & 48.21 & 47.63 & 46.12 & 42.80 & 39.64 \\
\hline Am242m & 4.82 & 5.01 & 4.87 & 4.63 & 4.33 \\
\hline $\mathrm{Am} 243$ & 15.63 & 14.55 & 14.94 & 17.53 & 18.16 \\
\hline $\mathrm{Cm} 242$ & 0.01 & 0.01 & 0.01 & 0.01 & 0.01 \\
\hline $\mathrm{Cm} 243$ & 0.17 & 0.19 & 0.24 & 0.27 & 0.28 \\
\hline $\mathrm{Cm} 244$ & 9.73 & 9.63 & 11.49 & 13.61 & 15.58 \\
\hline $\mathrm{Cm} 245$ & 3.35 & 3.36 & 3.84 & 4.42 & 5.18 \\
\hline $\mathrm{Cm} 246$ & 2.54 & 2.57 & 2.69 & 2.90 & 3.41 \\
\hline $\mathrm{Cm} 247$ & 0.52 & 0.53 & 0.51 & 0.53 & 0.62 \\
\hline $\mathrm{Cm} 248$ & 0.37 & 0.41 & 0.41 & 0.42 & 0.48 \\
\hline Total & 100.00 & 100.00 & 100.00 & 100.00 & 100.00 \\
\hline
\end{tabular}

Table 8 : Minor actinides isotopic vector comparison at end of irradiation cycle at equilibrium

Looking at Table 8 , the final inventory in minor actinides is directly linked to the transmutation performances of the strategy considered. The strategies with the highest transmutation rates also lead to a shift of the isotopic vector towards heavier curium isotopes, both in terms of mass and in terms of content. This shift is due to the higher level of flux which permits successive capture on curium isotopes and to the reprocessing of curium in the minor actinides. This can be seen while comparing Th/U-Pu/MA and U/TRU strategies for instance. The effect of this shift on fuel cycle parameters such as decay heat or neutron source is evaluated subsequently in this work.

c. Power levels in the blankets 
Power level variation in the blankets is due to the build-up of fissile isotopes during irradiation. One part is due to production of fissile material such as Am $242 \mathrm{~m}$ from the minor actinides initially loaded and the other part is explained by the support. Figure 9 shows the evolution of the power level in the blankets. For fissile-free strategies, we can observe an increase in the power level in the blankets due to the production of plutonium 239 or uranium 233. The sharp increase observed after five cycles is explained by the calculation scheme used, which adjusts the enrichment of the entire core to take into account the fissile material in the blankets, thus increasing the flux region. This also explains the behavior of the three other strategies.

Looking at Figure 9, it can be observed that the cases Th/U-Pu/MA and U/Pu/MA are very similar in terms in power level and power variation during irradiation. This is explained by the production of Pu239/U233 during the first phase of irradiation followed by a quasi-equilibrium state during the second irradiation phase. The minor actinides contribution is similar for each case. Power variation in the region is $144 \mathrm{MW}$ over ten reactor cycles for the thorium case and $113 \mathrm{MW}$ for the uranium one, which corresponds respectively to a $218 \%$ and $152 \%$ increase in blanket power.

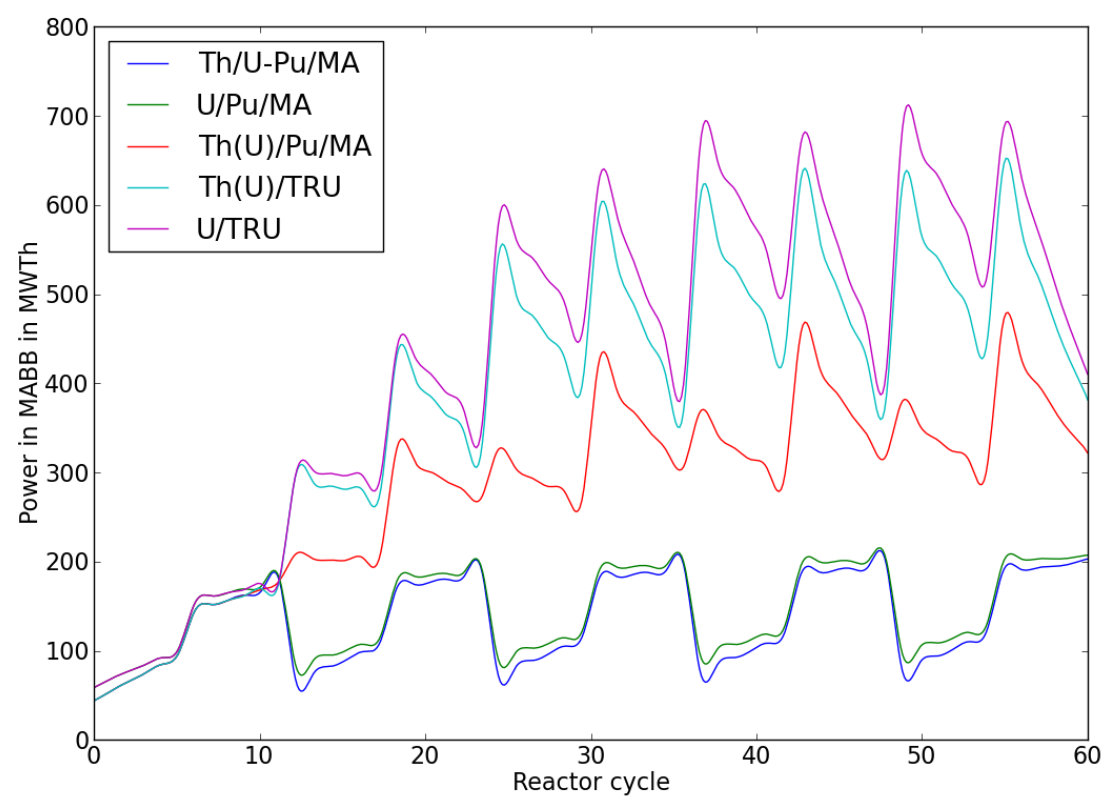

Figure 9 : Evolution of the power level in the blankets during irradiation

For the TRU cases, the power level can reach up to $720 \mathrm{MW}$ due to high fissile content in the blankets. This is equivalent to adding a new ring of fuel assemblies in the periphery of the core. In the case, the blankets assemblies are equivalent to fuel assemblies in terms of power at the end of irradiation but undergo a $45 \%$ increase in their power from 400 to $720 \mathrm{MW}$, compared to a $20 \%$ maximal increase for standard fuel assemblies. This high power variation may have adverse effects on fuel mechanical behavior, especially for swelling and fission gases release behavior [5].

The Th(U)/Pu/MA strategy is an intermediate one with a higher power level which may be beneficial for pins mechanical behavior compared to fissile-free strategy. The lower power variation limited to $193 \mathrm{MW}$ or a $156 \%$ increase, may also limits the constraints on the assembly design. As such, it may 
be interesting as a solution which could increase the transmutation performances without hindering assembly conception.

4. Comparison of uranium and thorium as support matrix for MABB : impact on fuel cycle parameters

In terms of fuel cycle, the estimators that were selected are the decay heat, gamma source and neutron source of the spent fuel. R\&D is currently still required to ascertain the feasibility of handling, reprocessing and manufacturing of minor actinides bearing blankets and we showed here that using thorium instead of uranium does not add new requirements to the fuel cycle part. The depletion calculations were performed using the DARWIN code package [24].

\section{a. Manufacturing and reprocessing of thorium oxide fuels}

An extensive review of the benefits and challenges associated with the thorium fuel cycle has been done by the IAEA in [12]. Generally speaking, the main challenge associated with thorium reprocessed is the industrial implementation and validation of the THOREX process developed at Oak Ridge in the fifties. This implementation requires the development of adequate shielding solutions to overcome the issue of high gamma emissions from uranium 232 daughter nuclei such as thallium 208, thorium 228 or lead 212. The presence of hard-to-extract protactinium 233 in the spent fuel is not an issue since its 27 days period means it has completely disappeared from the spent fuel after five years of cooling. A second challenge is the development and industrial validation of a process which can successfully separate and recover $\mathrm{U}, \mathrm{Pu}$ and the minor actinides from the spent fuel.

It should be noted here that the plutonium obtained from the separation of plutonium from thorium during recycling of the blankets may not be suited for military applications as its Pu 238 fraction is too high according to [23] , as shown in Figure 8.

b. Back end : Decay heat and neutron source

Decay heat per assembly is a dimensioning factor for the reprocessing flowsheet. A "hotter" fuel assembly will require extended cooling time before handling is possible or more expensive handling devices. Similarly, an equilibrium between longer cooling time and decreased reprocessing performances will have to be found as more active fuels degrades reprocessing efficiency [25]. 


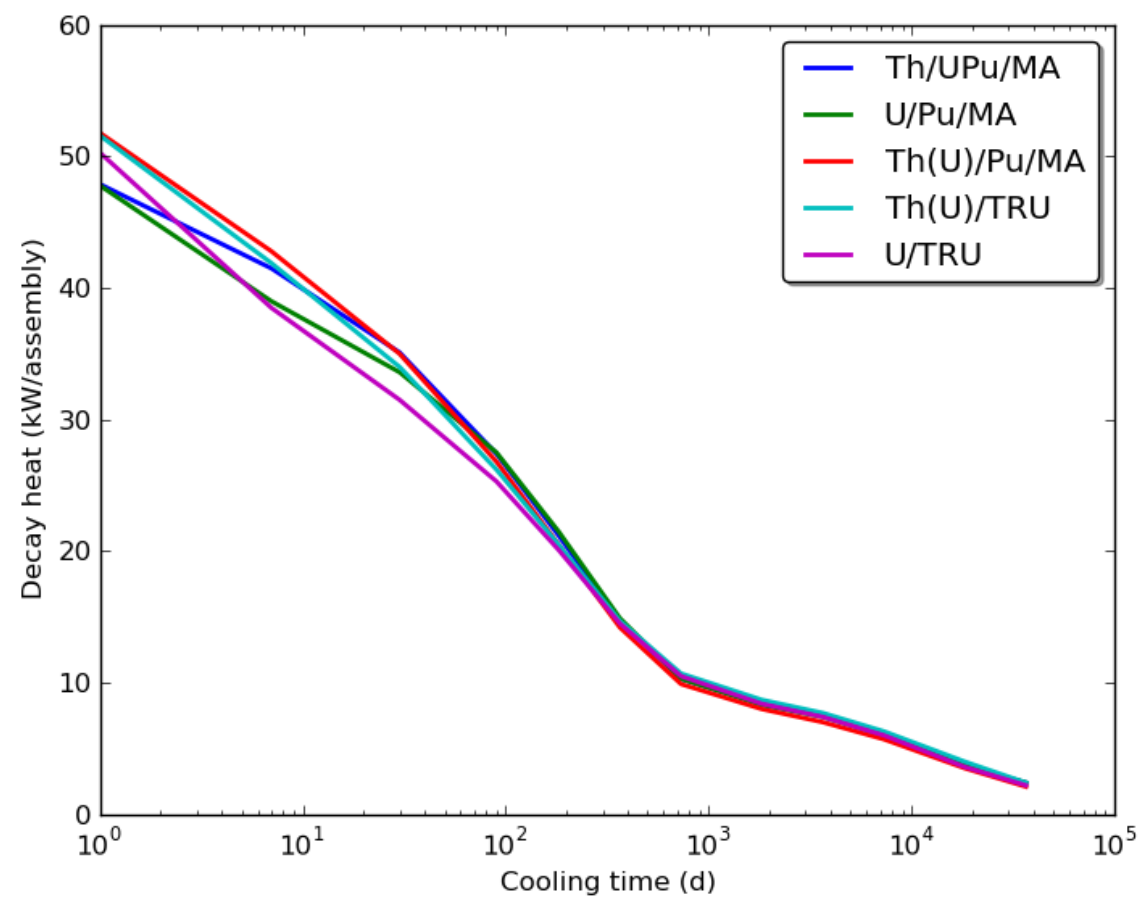

Figure 10 : Evolution of decay heat per assembly for each strategy

Time evolution of decay heat in the spent blanket assemblies can be separated in two steps as seen in Figure 10. The first one, from end of irradiation to about two years is characterized by a rapidly decreasing decay heat mainly fueled by short-lived fission products and curium 242 decay. The $\mathrm{U} / \mathrm{TRU}$ strategy is the less penalizing in terms of decay heat for this timescale as in this case curium 242 concentration has already peaked and actually started decreasing under irradiation. On the longer time scale, from two years to a century, the decay heat decrease is slower as the main contributors are Pu238 and $\mathrm{Cm} 244$, with half lives of 87.8 and 18.1 years. The decay heat for the $\mathrm{Th}(\mathrm{U}) / \mathrm{Pu} / \mathrm{MA}$ strategy is the lowest for this time scale, as more americium 241 has been consumed than in the fissile-free cases and less curium has been produced than in the TRU cases. Irradiated assemblies in the $\mathrm{Th}(\mathrm{U}) / \mathrm{Pu} / \mathrm{MA}$ are on the average $10 \%$ less active than those of $\mathrm{Th}(\mathrm{U}) / \mathrm{TRU}$, which is the most penalizing case.

If the impact of the strategy on decay heat is relatively limited, neutron source can change up to 30 $\%$ between the two extremal cases. Neutron source is mainly linked to curium isotopes heavier than curium 244 and is key factor for evaluating transportation and reprocessing feasibility, with regards both to radioprotection and criticality safety. In the U/TRU case, the plutonium accumulation in the blankets creates a reservoir for americium production and curium production onwards, which explains the higher neutron source associated with this strategy. In this case, using thorium as a support matrix leads to a reduction of $10 \%$ in the total neutron source on the short term. In both fissile-free strategies, the neutron source remains lower than $6 e 10 \mathrm{n} / \mathrm{s} / \mathrm{assembly}$ due to a low production of higher curium isotopes as it can be seen in in Table 8 . 


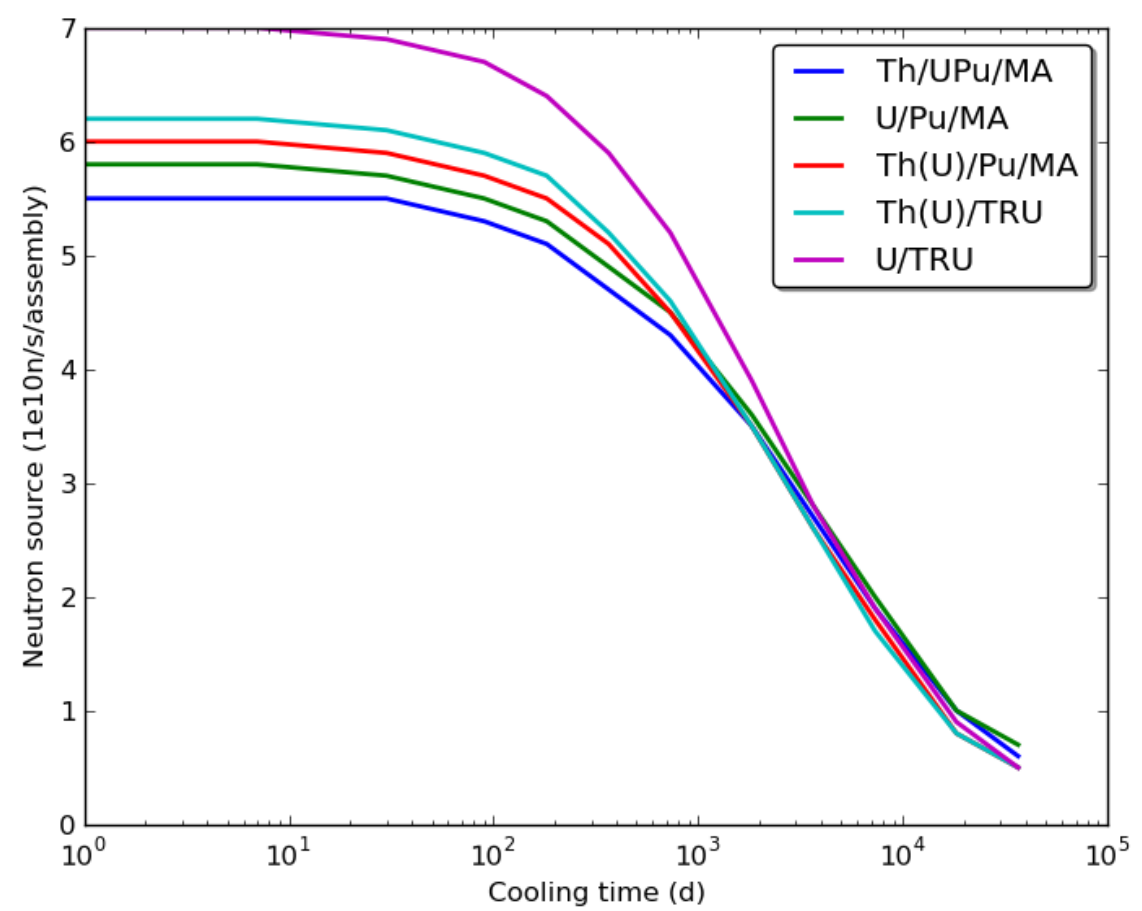

Figure 11 : Evolution of neutron source vs cooling time for each strategy

\section{c. Gamma emission}

A potential issue associated with the use of thorium is the increased gamma emission coming from thorium 228 and its daughter-nuclei or $\mathrm{Pa} 233$, which are strong gamma emitters [12]. The level and spectrum of gamma emission 30 days after the end of irradiation (assembly extraction of the core for relocation) and 5 years (typically expected cooling time) have been evaluated, to assess the shielding requirements both for handling the irradiated assembly during refueling operations and during reprocessing. The results are given in Figure 12 and Figure 13. A comparison of the total level of gamma emissions in each case is also given in Table 9. It should however be noted that due to the high content in minor actinides, remote handling will be necessary both for manufacturing and reprocessing of transmutation targets. 


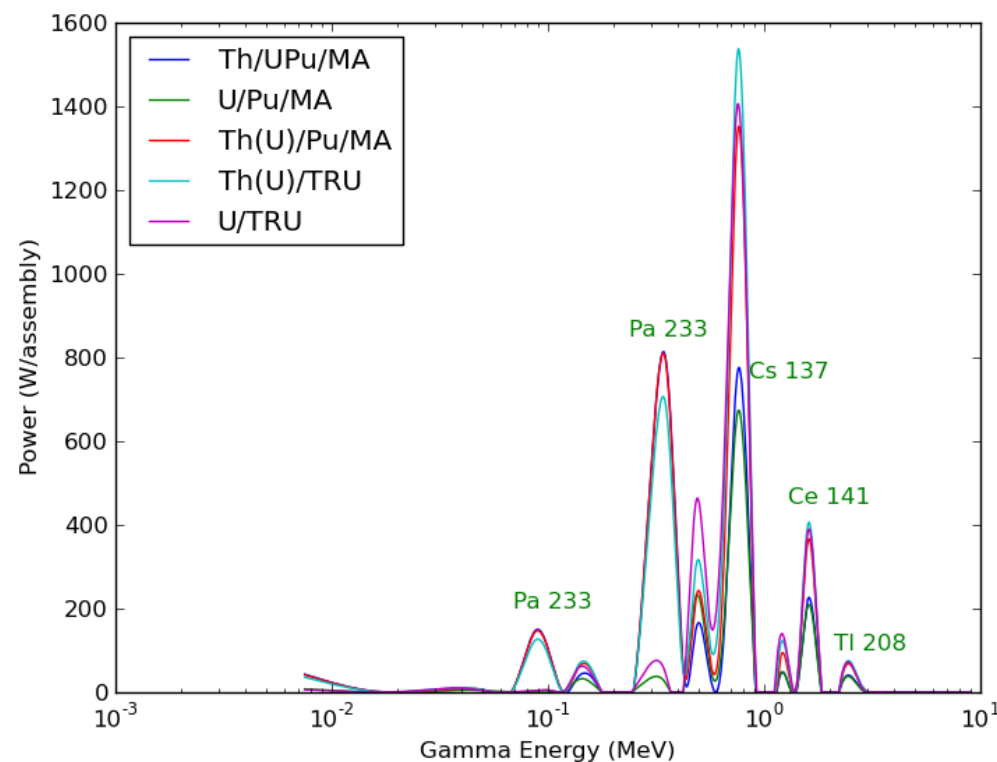

Figure 12 : Gamma spectrum after 30 days of cooling of irradiated CCAM assembly

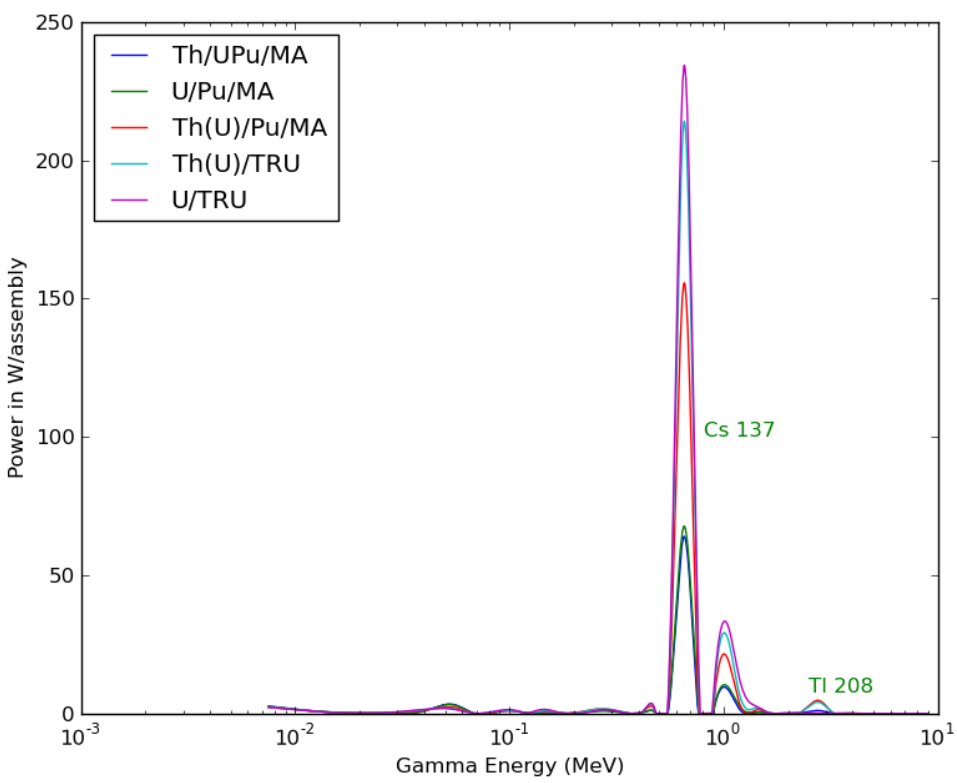

Figure 13 : Gamma spectrum at 5 years of irradiated CCAM with $U$ or Th support matrix 
Table 9 : Comparison of the total level of gamma emissions at the end of irradiation

\begin{tabular}{|c|c|c|c|c|c|}
\hline Strategy & $\begin{array}{c}\text { Th/U- } \\
\text { Pu/MA }\end{array}$ & U/Pu/MA & Th(U)/Pu/MA & U/TRU & Th(U)/TRU \\
\hline $\begin{array}{c}30 \text { days } \\
\text { (W/assembly) }\end{array}$ & 2559 & 1536 & 3680 & 3441 & 4081 \\
\hline $\begin{array}{c}5 \text { years } \\
\text { (W/assembly) }\end{array}$ & 89 & 95 & 208 & 327 & 289 \\
\hline
\end{tabular}

Concerning Figure 12, two remarks can be done. First, the presence of low energetic gammas from Protactinium 233 can be observed along with a small contribution from Thallium 208 in the $2 \mathrm{MeV}$ range. These two contributions are directly due to nuclei produced by capture on thorium or thorium disintegration chain and are thus not visible in the spectrum for the $U$ cases. The second point to make is that several peaks such as for Cs 137 or Ce 141 are corresponding to fissions products. The height of these peaks is linked to the amount of fissile material in the blankets and to the transmutation performances of the strategy.

Contrary to the decay heat and neutron source, it is expected that the evolution kinetic of gamma emission will be different between the two cases as the main emitters are not the same. However, as most of the gamma emissions (more than $70 \%$ ) come from fissions products which are roughly the same regardless of the support matrix, the difference in evolution time-scale is limited, as it can be seen on Figure 14.

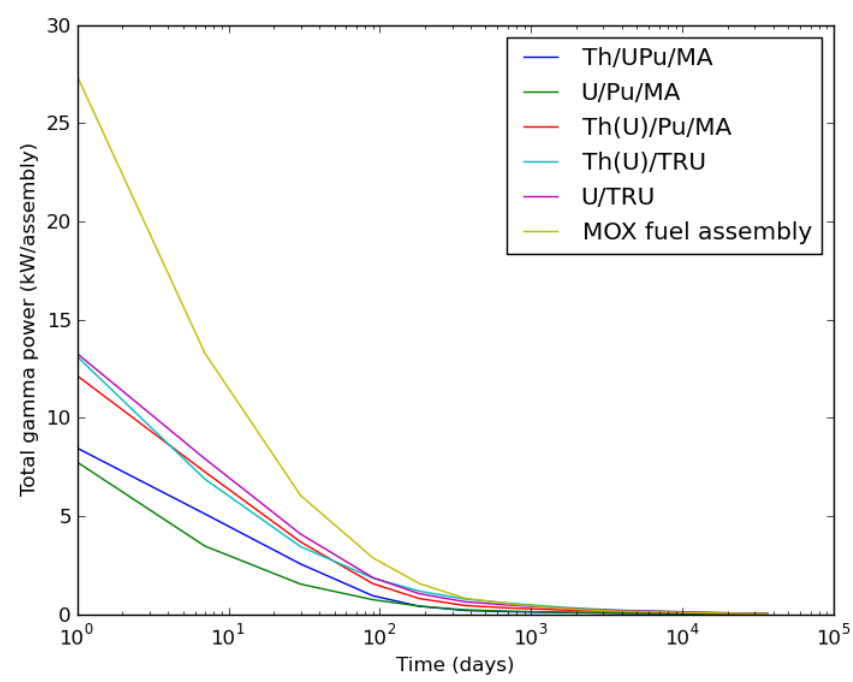

Figure 14 : Comparison of the evolution of gamma emissions for three cases

Regardless of the strategy, the total gamma emission of the blankets assembly is always lower than the one of a standard fuel assembly, as the one of such an assembly is dominated by fission products.

\section{d. Conclusion}

The conclusion of this analysis is that the use of thorium instead of uranium as support matrix for MABB will have a limited impact on spent fuel neutron source and decay heat, which means that no 
additional constraints have to be considered on the conditioning of the waste for final disposal. However, the increased number of fissions in the blanket assemblies in the thorium and TRU cases means that more fission products are going to be found in the assemblies to be reprocessed and thus the gamma emission of these elements will be higher compared to the fissile-free cases. Thorium itself was not found to have a significant impact on the gamma emission of the fuel elements except between 30 and 300 days where Protactinium 233 is responsible for up to $30 \%$ of the emission. The exact impact of the $2.6 \mathrm{MeV}$ gamma emitted by Thallium 208 on the fabrication and retreatment processed should be more thoroughly assessed in the future, notably in terms of additional shielding required. However, the high minor actinides content is likely to induce the need for adequate shielding, thus mitigating the increase in safety requirements for handling thallium 208.

\section{Conclusion}

We can compare the various strategies with the U/Pu/MA, which is the one currently envisioned in France [26]. This is done in Table 10. We can see that simply replacing uranium with thorium in the blankets and extracting the uranium 233 for use elsewhere yields performances lower than in the reference case, except for the impact on reactor operation due to the flatter $v$-value of the uranium 233 compared to Pu239.

Uranium 233 can also be left in the blankets to fasten the transmutation process. In this case, we compared a strategy where only uranium 233 is left to two strategies where all the transuranics elements are left in the blankets with either uranium or thorium support. Again, the thorium impact on core operation is lower. In terms of fissile inventory, the U/TRU case leads to the highest fissile inventory in the blanket while use of thorium leads to a $10 \%$ lower inventory. The neutron sources at 30 days and at five years are also lower in the thorium case due to a lower of production of heavy curium isotopes. In terms of decay heat, thorium is less effective at 30 days but leads to a lower long-term decay heat source.

Table 10: Global comparison of the five strategies previously discussed

\begin{tabular}{|c|c|c|c|c|c|}
\hline Strategy & $\begin{array}{c}\text { U/Pu/MA } \\
\text { (REF) }\end{array}$ & Th/U-Pu/MA & Th(U)/Pu/MA & Th(U)/TRU & U/TRU \\
\hline $\begin{array}{c}\text { Transmutation } \\
\text { rate (\%) }\end{array}$ & 39 & 37.4 & 48.5 & 53.3 & 56 \\
\hline $\begin{array}{c}\text { Sodium void } \\
\text { worth ( } \Delta \text { with } \\
\text { standard core } \\
\text { value, pcm) }\end{array}$ & +31 & $+24(-22.6 \%)$ & $+1(-96.8 \%)$ & $-7(-122 \%)$ & $+47(+153 \%)$ \\
\hline $\begin{array}{c}\text { Reactivity } \\
\text { swing (\% of } \\
\text { the standard } \\
\text { core) }\end{array}$ & 24 & $34(+41 \%)$ & $34(+41 \%)$ & $53(+121 \%)$ & $54(+125 \%)$ \\
\hline $\begin{array}{c}\text { Power in } \\
\text { blankets } \\
\text { (MW) }\end{array}$ & 5.64 & $5.4(+4.4 \%)$ & $10.5(+86.2 \%)$ & $13.5(+139 \%)$ & $14.7(+161 \%)$ \\
\hline
\end{tabular}




\begin{tabular}{|c|c|c|c|c|c|}
\hline $\begin{array}{c}\text { Power } \\
\text { variation in } \\
\text { blankets } \\
\text { during } \\
\text { irradiation } \\
\text { (MW) }\end{array}$ & 113 & 144 & 193 & 281 & 324 \\
\hline $\begin{array}{c}\text { Assembly } \\
\text { residual } \\
\text { power at } 30 \\
\text { days }\end{array}$ & 33.6 & $35.1(+4.5 \%)$ & $35,0(+4.2 \%)$ & $34,0(+1.2 \%)$ & $31,5(-6.3 \%)$ \\
\hline $\begin{array}{c}\text { Neutron } \\
\text { source at } 30 \\
\text { days }\end{array}$ & 5,46 & $5,70(+4.4 \%)$ & $5,92(+8.4 \%)$ & $6,10(+11.7 \%)$ & $6,87(+25.8 \%)$ \\
\hline $\begin{array}{c}\text { Fissile } \\
\text { material } \\
\text { inventory in } \\
\text { the blankets } \\
\text { at EOEC (kg) }\end{array}$ & 606 & $573(-5.4 \%)$ & $880(+45 \%)$ & $863(+42 \%)$ & $957.6(+58 \%)$ \\
\hline
\end{tabular}

It can be concluded that the use of thorium as a substitute for uranium support in minor actinides bearing blankets does not yield increased transmutation performances if the uranium 233 thus produced is extracted for use outside the blankets. On the other hand, the use of thorium blankets with a 'TRU' scheme in which all the transuranics, plutonium included, are left in the blankets for further irradiation yields similar performances to the uranium one albeit with a lower impact on the core parameters due to better neutronic behavior of uranium 233 and a lower overall fissile inventory by $16 \%$. The intermediate option of reusing only the uranium 233 produced in the blankets to speed up the transmutation process yields intermediate performances but require fine reprocessing of the irradiated fuel. This approach also increases the transmutation performances compared to a fissile-free approach while limiting the power variation in the blankets which is favorable in terms of assembly design. We can conclude from this work that the choice of thorium instead of as support matrix for heterogeneous transmutation targets cannot be decided in terms of transmutation performances only but requires careful analysis of the potential gains it can bring with regards to the overall fuel cycle.

\section{Bibliographie}

[1] NEA, «Status and assessement of fission products and minor actinides partitionning and transmutation,» NEA, Paris, 1999.

[2] M. SAlVATORES, A. ZAETTA, C. GIRARD, M. DELPECH, I. SLESSAREV et J. TOMMASI, «Nuclear Waste Transmutation, » AppL Radiat. Isot. , vol. 46, n%16/7, pp. 681-687, 1995.

[3] NEA, «Homogeneous versus heterogeneous recycling of transuranics in fast nuclear reactors,» 
NEA, Paris, 2012.

[4] C. Prunier, F. Boussard, L. Koch et M. Coquerelle, "Some specific aspects of homogeneous Am and $\mathrm{Np}$ based fuels transmutation through the outcomes of the superfact experiment in PHENIX fast reactor, " chez GLOBAL, 1993.

[5] J.-M. Bonnerot, S.Pillon, S.Béjaoui, E. D'Agata, R. Hania, N. Herlet, A. Jankowiak, M. Auclair, S. Bendotti, T. Lambert et B.Valentin, «Development programme on minor-actinide-bearing blankets at CEA,» chez IEMPT11, San Francisco, 2010.

[6] C. De Saint Jean, "Americium once-through of moderated targets in a CAPRA core,» chez Seminar Int. CAPRA conf, Karlsruhe, 1998.

[7] L. Buiron et e. al, «Heterogeneous minor actinides transmutation on a UO2 blanket and on $(\mathrm{U}, \mathrm{Pu}) \mathrm{O} 2$ fuel in sodium-cooled fast reactor. Assessment of core performances, ") chez GLOBAL, Paris, 2009.

[8] IAEA, «Status of minor actinides fuel development, "IAEA, Vienna, 2009.

[9] H. Matzke, V. Rondinella et T. Weiss, "Materials research on inert matrices: a screening study," Journal of Nuclear Materials, Vols. \%1 sur \%2I-II, n%1274, pp. 47-53, 1999.

[10] N. Chauvin, R. Konings et H. Matzke, «Optimisation of inert matrix fuel concepts for americium transmutation, „ Journal of Nuclear Materials, Vols. \%1 sur \%2I-II, n%1274, pp. 105-115, 1999.

[11] E. L. Ebert, G. Modolo, D. B. M. Cheng, M. Steppert et C. Walther, «Dissolution studies on molybdenum-based inert matrix fuels for the transmutation of minor actinides, " chez SACSESS, Warsaw, 2015.

[12] IAEA, «Thorium fuel cycle - Potential benefits and challenges,» IAEA, Vienne, 2005.

[13] P. Hania et F. Klaassen, «Volume 3: Advanced Fuels/Fuel Cladding/Nuclear Fuel Performance Modeling and Simulation,» chez Comprehensive Nuclear materials, 2012, pp. 87-108 .

[14] C. Lombardi, L. Luzzy, E. Padovani et F.Vettraino, «Thoria and inert matrix fuels for a sustainable nuclear power,» Progress in Nuclear Energy, vol. 50, pp. 944-953, 2008.

[15] W. S. You et S. G. Hong, "A neutronic study on advanced sodium cooled fast reactor cores withthorium blankets for effective burning of transuranic nuclides, " Nuclear Engineering and Design, vol. 278, pp. 274-286, 2014.

[16] K. Kawashima, K. Sugino, S. Ohki et T. Okubo, «Design study of a low sodium void reactivity core to accomodate degraded TRU fuel,» Nuclear Technology, vol. 3, n%1185, pp. 270-280, 2013.

[17] M. Ozawa, K. Yoshikazu, N. Kazunori et T. Yasumasa, «process, Separation of actinides and fission products in high-level liquid wastes by the improved TRUEX," Journal of Alloys and 
Compounds, Vols. \%1 sur \%2271-273, pp. 538-543, 1998.

[18] M.Meyer et e. al, «Scenarios for Minor Actinides Transmutation in the Frame of the French act for waste management, » IAEA, 2012.

[19] S.Bays, «Heterogeneous transmutation sodium fast reactor,» INL, Idaho Falls, 2008.

[20] G. Rimpault, «The ERANOS code and data system for fast reactor neutronic analyses, " chez PHYSOR, Seoul, 2002.

[21] A. Santamarina, «The JEFF-3.1.1 Nuclear Data Library,» OECD, Paris, 2009.

[22] P.Sciora, L.Buiron, G.Rimpault et F.Varaine, «A break even oxide fuel core for an innovative French sodium-cooled fast reactor : neutronic studies results,» chez GLOBAL, Paris, 2009.

[23] G. Kessler, «Plutonium denaturing by Pu-238,» Nuclear Science and Engineering, vol. 155, n%11, pp. 53-73, 2007.

[24] A. Tsilanizara, C. M. Diop, B. Nimal, M. Detoc, L. Lunéville, M. Chiron, T. D. Huynh, I. Brésard, M. Eid, J. C. Klein, B. Roque, P. Marimbeau, C. Garzenne, J. M. Parize et C. Vergne, « DARWIN: An Evolution Code System for a Large Range of,» Journal of Nuclear Science and Technology, vol. 37, pp. 845-849, 2000.

[25] Y. Gao, W. Zheng, X. Cao et S. Chen, «Influence of alpha and gamma radiolysis on Pu retention in the solvent TBP/kerosene,» Nukleonika, vol. 59, n%14, pp. 123-128, 2014.

[26] F.Varaine, L.Buiron, L.Boucher et C.Chabert, «Heterogeneous recycling in SFR core periphery,» chez PHYSOR, Interlaken, 2008.

[27] T. Kooyman et L. Buiron, «Sensitivity analysis of minor actinides transmutation to physical and technological parameters, " chez GLOBAL2015, Paris, 2015.

[28] Y. Kobayashi et A. Saito, "The extraction of thorium, neptunium, plutonium and americium with sodium amalgam from aqueous solution," Journal of Inorganic and Nuclear Chemistry, vol. 35, n%110, pp. 3605-3610, 1973.

[29] «Compendium of Dose Coefficients based on ICRP Publication 60. ICRP Publication 60,» Ann. ICRP, $\mathrm{n}^{\circ} \% 141,2012$. 